\title{
Delegation and firms' ability to collude
}

\author{
Luca Lambertini ${ }^{\mathrm{a}}$, Marco Trombetta ${ }^{\mathrm{b}, *}$ \\ a University of Bologna, Bologna, Spain \\ ${ }^{\mathrm{b}}$ Universidad Carlos III de Madrid, Madrid, Spain
}

\begin{abstract}
In a model of repeated Cournot competition under complete information, we show that delegation has no effect on cartel stability if managers collude, while it may hinder cartel stability when owners collude in setting the incentive schemes If owners can choose whether to delegate or keep control of their respective firms, and both groups of individuals collude or play non-cooperatively in their respective variables according to the level of intertemporal discount factor, then if managers are not able to collude in output levels, owners' delegation decision is non-monotone in the discount factor
\end{abstract}

JEL classification: D43; L13; L21

Keywords: Delegation; Cartel stability

\section{Introduction}

The issue of cartel stability has received a great deal of attention in the recent literature. Several aspects of the competitive conditions characterising market interaction may affect firms' ability to reach a collusive agreement and maintain it over time. d'Aspremont et al. (1983), Donsimoni (1985) and Donsimoni et al. (1986) have dealt with the consequences of heterogeneity among agents on cartel stability. In another vein, Green and Porter (1984), Rees (1985) and Rotemberg and Saloner (1986) have focused upon the role of imperfect information. The common feature characterising these streams of research is that they all deal with elements which are exogenously given and, as such, cannot be affected by firms' behaviour. How about factors that, on the contrary, can be manipulated to some extent before market competition or collusion takes place? A lot of effort has been produced in analysing

\footnotetext{
* Corresponding author Calle Madrid 126, Getafe, 28903 Madrid, Spain Tel : +34-91-6249642; fax: +34-91-6249608

E-mail address: mtrombet@emp uc3m es (M Trombetta)
} 
the interaction between the stability of collusion and the degree of product differentiation (see, inter alia, Deneckere (1983), Chang (1991), Ross (1992), Häckner (1994), Häckner (1995), Lambertini (1997), Lambertini et al. (1998) and Albæk and Lambertini (1998)). This literature offers ambiguous results.

Here, we want to address whether the sustainability of collusion can be affected by delegating control to managers who do not necessarily aim at strict profit maximisation. The delegation issue was introduced in the literature by Fershtman (1985) and Vickers (1985), who showed that delegation is a dominant strategy in a one-shot non-cooperative game, in that delegation makes the firm more aggressive under Cournot competition and creates a credible commitment towards output expansion. This idea has been developed in several directions since (see Fershtman and Judd (1987), Sklivas (1987), Basu (1995) and Lambertini (2000)). A few contributions in this field focus on the possibility for delegation to enhance firms' ability to reach a cooperative outcome in one-shot games (Fershtman et al., 1991; Polo and Tedeschi, 1992). From these papers it emerges that, even in strictly non-cooperative games, cooperative outcomes arise as equilibria of the delegation game, provided every principal is committed to the contract signed with the agent and contracts are publicly observable. The fact that contracts are common knowledge opens the possibility that they may be conditioned upon in the agents' subgame. ${ }^{1}$ The cooperative outcomes obtained in these papers are in strong contrast with those reached by Vickers (1985), Fershtman and Judd (1987) and Sklivas (1987), where the agents' behaviour is not conditional on the compensation scheme agreed upon with their respective principals. Barcena-Ruiz and Paz Espinoza (1996) address the issue of the optimal duration of delegation contracts under either price or quantity competition. They find that the slope of owners' reaction function at the incentive stage always replicates the slope of reaction functions at the market stage. As a result, the best reply to a long-term contract is a long-term contract, if downstream competition takes place in quantities, while it is a short-term contract if the market stage is played in the price space. An alternative justification for the use of delegation is given by Zábojník (1998). Shareholders may find it optimal to provide managers with incentives to maximise sales in addition to profits in the presence of a double agency problem. In this case, the compensation contract between shareholders and the executive not only affects executive's market decisions, but also provides a remedy to the underinvestment in human capital by workers. These theoretical grounds for revenue maximisation are in line with the empirical evidence provided by Murphy (1985) and Baker et al. (1988), concerning the causal relation between firms' sales and executive's remuneration.

Adopting the same framework introduced by Vickers (1985), we investigate here whether delegation may influence firms' ability to sustain implicit cartel agreements in repeated games.

We consider three different settings. First, we tackle the case where collusion takes place between managers, while shareholders play non-cooperatively. We show that delegation contracts are always symmetric and that the separation between ownership and control does

\footnotetext{
${ }^{1}$ As shown by Katz (1991), if contracts were unobservable then delegation would have no effect on the equilibrium of the game, i e it would be the same as in the game without agents See, in particular, Corollary 1 (Katz (1991), p 315) See also Barcena-Ruiz and Paz Espinoza (1996), p 348
} 
not affect firms' incentive to collude, since any pair of symmetric contracts is perceived by managers as a symmetric shift downwards (upwards) of the cost (demand) function. Second, we consider the case where collusion takes place between principals in designing the delegation contracts, under the assumption that managers behave non-cooperatively throughout the supergame. In this setting, we prove that, if delegation contracts are symmetric, delegation reduces the stability of an implicit cartel agreement between owners in that it makes deviation more appealing as compared to a situation where firms are strict profit-seeking agents. Third, we investigate a fully-fledged setting where owners decide whether to delegate or not and, if they do, both groups of individuals either implicitly collude or behave non-cooperatively in setting their respective variables, according to their intertemporal preferences and the relevant critical levels of discount factors. In this case, we show that when managers are prone to collusion, i.e. sufficiently patient, then this guarantees that owners always obtain a collusive outcome even if they play non-cooperatively. In other words, the optimal collusive incentive scheme and the optimal non-cooperative incentive scheme are observationally equivalent. Otherwise, when managers are not sufficiently patient to collude in the market variable, this may not preclude entrepreneurs' ability to enjoy collusive profits if their intertemporal discount factor is sufficiently high. Hence, it emerges that owners' delegation decisions are non-monotone in their individual discount factor, provided that managers are unable to collude at the market stage. When owners' discount factor is extremely low, they can not avoid delegating, due to a prisoner's dilemma. Then, there is a range of discount factors for which owners do not delegate, reaching first the Pareto-efficient payoff of the static game and then the collusive payoff. Finally, for sufficiently high values of the owners' discount factor, given owners' ability to collude while setting the incentive scheme, delegation becomes again the optimal choice.

The remainder of the paper is structured as follows. Section 2 introduces the basic model. Then, the setting where collusion takes place between agents is dealt with in Section 3, while Section 4 describes the alternative case in which owners try to collude by optimally designing their respective delegation contracts. The situation where both groups try to achieve implicit collusion and the optimal choice between delegation and non delegation are treated in Sections 5 and 6. Finally, Section 7 provides concluding remarks.

\section{The set-up}

We adopt the same model as in Vickers (1985). Two firms, which we label $i$ and $j$, compete in quantities on a market for a homogeneous product, whose inverse demand function is

$$
p=A-x_{i}-x_{j} .
$$

Under the assumption that production takes place at constant returns to scale, the profit function of firm $i$ looks as follows:

$$
\pi_{i}=(p-c) x_{i}
$$

where parameter $c<A$ is the unit production cost. 
If a firm's owner decides to delegate control over her own assets to a manager, the objective of the latter is

$$
\max _{x_{i}} \quad M_{i}=\pi_{i}+\theta_{i} x_{i}
$$

where $\theta_{i}$ measures the relevance of sales, and is to be optimally set by the principal in the delegation contract, in order to maximise profits. ${ }^{2}$

In the remainder, we are going to consider three different situations, where (i) managers collude while owners play non-cooperatively; (ii) owners collude while managers play non-cooperatively; and (iii) both groups try to collude. In each setting, the basic stage game is repeated infinitely many times, over $[0, \infty)$. Let $\alpha_{i} \in[0,1]$ define manager $i$ 's individual discount factor, and $\delta_{i} \in[0,1]$ define owner $i$ 's individual discount factor. We adopt the following assumption:

Assumption 1. $\alpha_{i}=\alpha_{j}=\alpha$ and $\delta_{i}=\delta_{j}=\delta$.

This amounts to assuming that players are pairwise symmetric as far as their intertemporal preferences are concerned.

When the game is repeated, the incentive scheme is set at the beginning of each period. Managers can be substituted at the beginning of each period, for example when they die or retire, but the new manager will share the same characteristics of the old manager. In particular he/she will have the same discount factor. Hence, the model can be solved as if the managers had infinite working lives with the firm.

The measure of cartel stability used is the critical threshold of the discount factor as yielded by Friedman's "grim" strategies (Friedman, 1971). We consider the case where players collude on the maximisation of the joint payoff. ${ }^{3}$ Each player colludes as long as the rival does likewise. After detecting a deviation by either of them, say in period $t \in[0, \infty)$, both players revert to the non-cooperative equilibrium strategy forever, from period $t+1$ to $\infty$. Let $\sigma^{*}$ define the critical threshold of the discount factor, in the case of collusion in quantities in a symmetric setting where players are strict profit-seeking firms. They are able to sustain tacit collusion over time if and only if their discount factor satisfies the following condition:

$$
\sigma \geq \sigma^{*}=\frac{\pi_{i}^{\mathrm{D}}-\pi_{i}^{\mathrm{C}}}{\pi_{i}^{\mathrm{D}}-\pi_{i}^{\mathrm{N}}}=\frac{9}{17}
$$

where $\pi_{i}^{\mathrm{D}}, \pi_{i}^{\mathrm{C}}$ and $\pi_{i}^{\mathrm{N}}$ define the profits accruing to firm $i$, respectively, (i) when she deviates from the collusive agreement; (ii) when both firms collude; and finally (iii) when firms play

\footnotetext{
${ }^{2}$ Managerial remuneration is a two-part wage consisting in a component increasing in $\theta_{i}$ and a constant which is set so as to pay the manager his required wage for each level of $M_{i}$, i e $w_{i}\left(M_{i}\right)=A_{i}+B_{i} M_{i}$ We do not assume a competitive market for managers and so managers do not necessarily receive just their reservation wage Hence, while maximising their objective function, managers are also maximising their remuneration In Appendix A, it is shown that the formulation due to Vickers (1985) and that due to Fershtman and Judd (1987) are equivalent

${ }^{3}$ We do not consider the case of partial collusion (for an introduction, see Gibbons (1992)) We examine grim strategies for the sake of comparison with a large part of the existing literature, although grim strategies are not optimal (symmetric optimal punishments have been modelled by Abreu (1986) and Abreu et al (1986))
} 
non-cooperatively. Textbook calculations are needed to verify that the critical value of the discount factor in such a setting is indeed that shown in (4). We adopt it as a benchmark in the remainder of the paper, where we use $\delta^{*}$ and $\alpha^{*}$ to indicate the owners' and the managers' critical level of the discount factor, respectively.

\section{Collusion between managers}

We begin with the analysis of the case where collusion can take place only in the market stage, i.e. between agents. As to the behaviour of owners in the delegation stage, we have to describe their respective value of $\theta_{i}$. We introduce the following assumption:

\section{Assumption 2. If $\theta_{j}>\theta_{i}$, then managers will play non-cooperatively}

It is easy to show that, if manager decided to collude and maximise joint surplus, then the solution would be at a corner where the agent with the higher $\theta$ (smallest perceived cost) produces the optimal quantity given market demand, whereas the other agent accepts not to produce. But if this is the case, then the manager with the higher $\theta$ should accept to share the surplus with the other manager. In order to do that, some form of side payments should be used. The sustainability of such an agreement is obviously highly questionable.

Moreover, given the symmetry between owners, we will see that asymmetric incentive schemes can arise only during a deviation phase from a collusive equilibrium between owners. Such a phase would last only for one period. It is difficult then to imagine a collusive agreement based on incentive schemes that are going to be in place only for one period. ${ }^{4}$

First of all, we prove the following lemma:

Lemma 1. If owners play non-cooperatively, then incentive schemes, as well as output levels are always symmetric.

Proof. Given Assumption 2, if incentives are asymmetric, then managers play noncooperatively. Vickers (1985) already showed that the non-cooperative equilibrium with non-cooperative managers involves a symmetric incentive scheme. Hence, asymmetric incentive schemes can not be part of an equilibrium. ${ }^{5}$

The symmetry between incentive schemes is going to play a relevant role in the remainder of the analysis. The objective function of the managers at the market stage can be rewritten as follows:

$$
M_{i}=\left(A-x_{i}-x_{j}-\gamma_{i}\right) x_{i}
$$

where $\gamma_{i}=c-\theta_{i}$. This entails that delegation mimics a change in the unit production cost. On the basis of Lemma 1, at equilibrium $\theta_{i}=\theta_{j}=\theta$. Hence, it must also be that $\gamma_{i}=\gamma_{j}=\gamma$, i.e. the perceived change in the unit cost has to be the same for both firms.

\footnotetext{
${ }^{4}$ However, it is possible to show that all the main results of the paper hold when managers are allowed to collude under an asymmetric incentive scheme and share the surplus equally The proof is avaiable from the authors

${ }^{5}$ Vickers (1985) analysis will be quickly presented in Section 4
} 
Define now $M_{i}^{\mathrm{N}}, M_{i}^{\mathrm{C}}, M_{i}^{\mathrm{D}}, M_{i}^{\mathrm{Ch}}$ as, respectively, the payoffs accruing to the manager of firm $i$ in the Cournot-Nash equilibrium; in the collusive equilibrium; in the case of deviation by firm $i$, while the manager of firm $j$ sticks to his cartel output level; and finally, in the case where the opposite happens (here, superscript $\mathrm{Ch}$ stands for cheated). Then, define the critical threshold of the discount factor stabilising collusion as

$$
\alpha^{*}=\frac{M_{i}^{\mathrm{D}}-M_{i}^{\mathrm{C}}}{M_{i}^{\mathrm{D}}-M_{i}^{\mathrm{N}}}
$$

It is immediate to verify that in any payoff $M_{i}^{\mathrm{J}}=\beta^{\mathrm{J}}(A-\gamma)^{2}, \beta^{\mathrm{J}}$, which is the relevant numerical coefficient under the market regime $\mathrm{J}$, is the same with and without delegation. As a result,

$$
\alpha^{*}=\sigma^{*}=\frac{9}{17},
$$

i.e. the critical level of the discount factor coincides with that emerging from the game without delegation, where collusion occurs between entrepreneurs (detailed calculations are in Appendix B). Consequently, the outcome of this setting can be summarised by the following proposition.

Proposition 1. When owners play non-cooperatively and collusion takes place between managers, incentive scheme are symmetric and delegation does not affect cartel stability.

Provided that owners provide their respective managers with any pair of symmetric contracts, the attempt at colluding on the part of the agents is completely equivalent, in terms of its stability, to its counterpart when firms are strict profit-seekers. The shift perceived either in the linear cost function or in the linear market demand function is unable to affect the incentive structure that characterises the supergame.

\section{Collusion between owners}

We now consider the case where owners can collude in setting the value of $\theta_{i}$, while managers behave à la Cournot, non-cooperatively and simultaneously choosing their respective production levels. The first-order condition (FOC) facing firm $i$ 's manager in the market subgame is

$$
\frac{\partial M_{i}}{\partial x_{i}}=A+\theta_{i}-c-2 x_{i}-x_{j}=0 .
$$

Solving yields the optimal outputs in terms of the delegation parameters:

$$
x_{i}=\frac{A-c+2 \theta_{i}-\theta_{j}}{3} ; \quad x_{j}=\frac{A-c+2 \theta_{j}-\theta_{i}}{3} .
$$

Substituting and rearranging, we get the following profit function for firm $i$ :

$$
\pi_{i}=\frac{\left(A-c+2 \theta_{i}-\theta_{j}\right)\left(A-c-\theta_{i}-\theta_{j}\right)}{9} .
$$


The reaction function of firm $i$ 's owner is

$$
\theta_{i}=\frac{A-c-\theta_{j}}{4}
$$

so that non-cooperative profit maximisation w r.t. $\theta_{i}$ and $\theta_{j}$ is reached when $\theta_{i}^{\mathrm{N}}=\theta_{j}^{\mathrm{N}}=$ $(A-c) / 5$, equilibrium profits amounting to $\pi_{i}^{N}=2(A-c)^{2} / 25$, obviously lower than those associated with a Cournot-Nash equilibrium between profit-maximising firms (see Vickers (1985), p.142).

We are now in a position to investigate the cartel solution, where owners choose $\theta_{i}$ and $\theta_{j}$ in order to maximise joint profits, $\Pi=\pi_{i}+\pi_{j}$. It is easy to check that joint profits are maximised by any pair of incentive schemes such that

$$
\theta_{i}+\theta_{j}=\frac{(c-A)}{2}
$$

Assumption 3. If owners decide to collude, they adopt a symmetric incentive scheme, i.e. $\theta_{i}^{\mathrm{C}}=\theta_{j}^{\mathrm{C}}=\theta^{\mathrm{C}}$.

If managers decide to collude, but they adopt an asymmetric incentive scheme, then the actual distribution of profits will also be asymmetric and in many cases collusion will have to be sustained by transfers between firms. In order to avoid this, which would be illegal and possibly reveal collusion, and to be consistent with Assumption 1, we assume that asymmetric incentive schemes can be adopted only during a deviation phase, but not in a collusive equilibrium. Assumption 3 and Lemma 1 guarantee that asymmetric incentive schemes will never be observed in equilibrium. ${ }^{6}$

Setting $\theta_{i}=\theta_{j}=\theta$ and solving, we obtain $\theta^{\mathrm{C}}=(c-A) / 4<0$, while collusive profits are $\pi_{i}^{\mathrm{C}}=\pi_{j}^{\mathrm{C}}=(A-c)^{2} / 8$. Notice that they coincide with the individual cartel profit under strict profit-maximising behaviour.

If, say, firm $j$ 's owner sticks to the cartel level of $\theta_{j}$, while the owner of firm $i$ deviates along his best reply function (11), we get $\theta_{i}^{\mathrm{D}}=5(A-c) / 16$, entailing the following profits:

$$
\pi_{i}^{\mathrm{D}}=\frac{25}{128}(A-c)^{2} ; \quad \pi_{j}^{\mathrm{Ch}}=\frac{5}{256}(A-c)^{2} .
$$

The deviation profit is higher than the corresponding magnitude that would be observed if firms were entrepreneurial. The value of the critical discount factor turns out to be

$$
\delta^{*}=\frac{25}{41} \text {. }
$$

Observe that $\sigma^{*}<\delta^{*}$. We can summarise the above analysis as follows:

Proposition 2. When collusion takes place between owners, while managers behave noncooperatively, collusion is harder to sustain as compared to the case where firms are strict profit-seekers.

\footnotetext{
${ }^{6}$ If incentive schemes are always symmetric and managers are identical, then managers remunerations are also always symmetric, i e $A_{i}=A_{j}$ and $B_{i}=B_{j}$
} 
This result can be given the following intuitive interpretation. Individual cartel profit being independent of the internal organisation of firms, the critical level of the discount factor is higher in the presence of delegation because (i) the one-shot Nash equilibrium profit decreases, while (ii) the deviation profit increases as compared to the fully entrepreneurial setting, and (iii) the increase in the latter outweighs the decrease in the former, yielding a more unstable cartel by making deviation more attractive than it is when entrepreneurs are running their respective firms.

\section{Two-sided collusion}

We can now combine the cases presented so far and analyse the fully fledged setting where managers have the opportunity to decide whether to collude or not after owners have set their incentives, either collusively or non-cooperatively. The game takes place over the time horizon $[0, \infty)$ and is organised in three stages, as follows.

Stage 1: at time $t=0$, owners decide whether to delegate or not. The strategy set is $\Omega=\{e, m\}$, where $e$ stands for entrepreneurial, while $m$ stands for managerial.

If both either do or do not, then

Stage 2: from $t=1$ onwards, owners either collude or play non-cooperatively, according to their intertemporal discount factor and the related stream of discounted profits. In case of delegation, they set the value of $\theta$ appropriately. Otherwise, they set outputs to maximise joint profit. The strategy set is $\Psi=\left\{C, N, \theta_{i}\right.$ if $m$, or $x_{i}$ if $\left.e\right\}$.

Stage 3: from $t=1$ onwards, managers decide whether to collude or to play noncooperatively, according to their intertemporal discount factor and the related stream of discounted payoffs. The strategy set is $\Phi=\left\{C, N, x_{i}\right.$ if $\left.e\right\}$.

If only one owner delegates at $t=0$, then

Stage 2: from $t=1$ onwards, the owner of the managerial firm sets $\theta$ so as to maximise her individual non-cooperative profit.

Stage 3: from $t=1$ onwards, the owner of the entrepreneurial firm and the manager of the rival firm non-cooperatively set their respective quantities. The decision tree associated with the game is illustrated below showing discounted profits per firm.

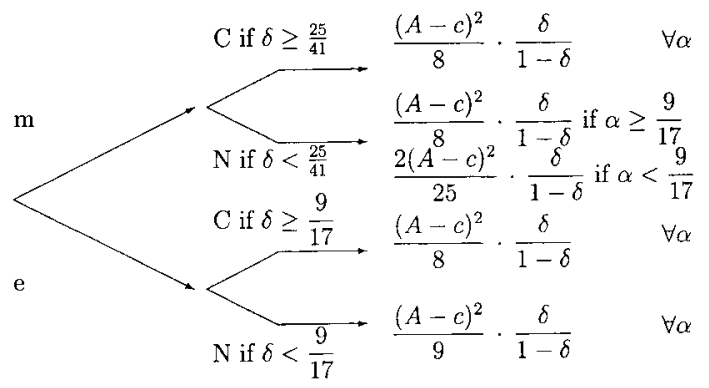

Observe that the tree exclusively features symmetric decisions and discounted payoffs. Below, we deal with the three relevant asymmetric situations that can arise, namely, 
(i) one-sided delegation; (ii) a deviation takes place between owners, while managers are trying to collude; and (iii) a deviation takes place between owners, while managers are playing non-cooperatively.

\subsection{The delegation dilemma revisited}

Here, we briefly examine the possibility for owners to avoid delegation in an infinitely repeated game. This opens a perspective where owners may indeed be able to avoid the separation between ownership and control, but still they may prefer to delegate because managers are more patient than owners. Hence, delegation can allow owners to gain collusive profits they could not obtain by themselves.

The one-shot setting originally presented by Vickers (1985) belongs to the prisoner's dilemma family, the relevant per period profits being $\pi_{i}^{\mathrm{N}}(m ; m)=\left[2(A-c)^{2}\right] / 25$ when both firms are managerial, $\pi_{i}^{\mathrm{N}}(e ; e)=(A-c)^{2} / 9$ when both are entrepreneurial, and $\pi_{i}^{\mathrm{N}}(e ; m)=$ $(A-c)^{2} / 16 ; \pi_{j}^{\mathrm{N}}(m ; e)=(A-c)^{2} / 8$ when firm $i$ is entrepreneurial while firm $j$ is managerial. The Nash equilibrium of the game involves delegation by both owners, but this is not Pareto efficient, because both owners would be better off if they did not delegate. However, both owners are led to delegate since it represents a dominant strategy, i.e. the willingness of each owner to be the only one to delegate drives the result. If Vickers' game is repeated an infinite number of times, and at the market stage the agents always play à la Cournot-Nash, then it is easy to show that collusion on the "no delegation" decision is sustainable if

$$
\delta \geq \frac{25}{81} .
$$

Moreover, observe that the profit accruing to the managerial firm, when the rival is a strict profit-seeker, exactly corresponds to the collusive payoff yielded by symmetric cartel behaviour. Hence, if at time $t=0$ firm $i$ 's owner chooses not to delegate, it appears reasonable to assume that no collusion is going to take place from $t=1$ onwards, for two related reasons. The first is that the strategic variables to the avail of players differ: once firm $i$ has decided to remain entrepreneurial, its owner must compete on the market with the manager of the rival firm, and does not directly interact with the other owner. Second, as a consequence, the owner of the entrepreneurial firm cannot expect the owner of the managerial firm to set $\theta$ so as to maximise joint profit, and vice versa.

\subsection{Deviation under two-sided collusion}

Consider now the case where both owners decide to delegate. They have to decide whether to collude while choosing $\theta$, or not. Given Lemma 1 and Assumption 3, in both the collusive and the non-cooperative Nash equilibrium they will choose $\theta_{i}=\theta_{j}=\theta$. Then we already know that, if this is the case, managers will play collusively if $\alpha \geq 9 / 17$, and non-cooperatively if $\alpha<9 / 17$. We consider these two cases separately.

\subsubsection{Patient managers $(\alpha \geq 9 / 17)$}

If managers are patient, then we know from Section 3 that they will collude if faced with $\theta_{i}=\theta_{j}=\theta$, and, in order to avoid transfers, they will set 


$$
x_{i}^{\mathrm{C}}=x_{j}^{\mathrm{C}}=x^{\mathrm{C}}=\frac{A-c+\theta}{4}
$$

Consequently, the owners' payoffs become

$$
\pi_{i}=\pi_{j}=\pi^{\mathrm{CC}}=\frac{(A-c)^{2}-\theta^{2}}{8},
$$

which leads to an optimal choice of

$$
\theta_{i}=\theta_{j}=\theta^{\mathrm{C}}=\theta^{\mathrm{N}}=0
$$

In other words, if managers are patient, owners will always choose $\theta=0$ as the optimal incentive scheme no matter how they decide to play. Intuitively, if managers are going to collude, then owners anticipate that and by forcing the managers to strictly maximise profits, they get the maximum feasible payoff, i.e. collusive profit, and this holds even if they decide to play non-cooperatively. But if this is the case, there is no incentive to collude in the first place.

Proposition 3. If managers are patient $(\alpha \geq 9 / 17)$, owners will always play noncooperatively, enjoying however the collusive outcome.

\subsubsection{Impatient managers $(\alpha<9 / 17)$}

Given Assumption 2, after a deviation managers will keep on playing non-cooperatively. Consequently, managers will always play non-cooperatively. Hence, the results found in Section 4 apply and owners will collude on $\theta^{\mathrm{C}}=(c-A) / 4$ as long as $\delta \geq 25 / 41$.

\section{Solving the supergame}

We are now in a position to characterise the subgame perfect equilibria of the supergame under two-sided collusion. We first deal with the cases where managers are impatient $(\alpha<9 / 17)$.

\subsection{Impatient managers $(\alpha<9 / 17)$}

Given Assumption 2, here, managers will always play à la Cournot-Nash, no matter what is the incentive they face. Four relevant ranges can be identified for the owners' factor $\delta$.

1. $\delta \in(0,25 / 81)$. In this range, no group can collude, and owners are unable to avoid delegation. Hence, the subgame perfect equilibrium of the supergame is characterised as follows. Owners: $(m, N)$; managers: $N$. Per period individual profit is $\pi_{i}^{\mathrm{N}}(m ; m)=$ $\left[2(A-c)^{2}\right] / 25$.

2. $\delta \in[25 / 81,9 / 17)$. In this range, no group can collude, but owners are able to avoid delegation. Thus, the subgame perfect equilibrium of the supergame is characterised as follows. Owners: $(e, N)$; managers: $N$. Per period individual profit is $\pi_{i}^{\mathrm{N}}(e ; e)=$ $(A-c)^{2} / 9$. 
3. $\delta \in[9 / 17,25 / 41)$. In this range, owners are in a position to collude in quantities if they do not delegate, while they are unable to collude in setting the incentive schemes. Hence, the subgame perfect equilibrium of the supergame is characterised as follows. Owners: $(e, C)$, managers: $N$. Per period individual profit is $\pi_{i}^{\mathrm{C}}(e ; e)=(A-c)^{2} / 8$.

4. $\delta \in[25 / 41,1)$. In this range, owners are in a position to collude in any variable, as well as to avoid delegation. Consequently, the subgame perfect equilibrium of the supergame is characterised as follows. Owners: $(m, C)$; managers: $N$. Per period individual profit is $\pi_{i}^{\mathrm{C}}(m ; m)=(A-c)^{2} / 8$.

It is useful to represent this setting as a game in normal form. This is done in Matrix 1. ${ }^{7}$

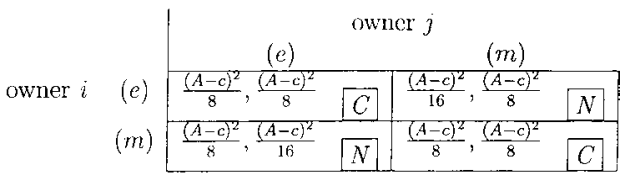

Matrix 1

The north-west cell of Matrix 1 contains cartel profits in that owners will collude if the keep control of their respective firms, in this range of $\delta$. It is immediate to check that $\{(m, C),(m, C)\}$ is the unique subgame perfect equilibrium of the game and is Pareto-optimal. $\{(e, C),(e, C)\}$ is also a Nash equilibrium, but it involves weakly dominated strategies and hence cannot be subgame perfect. Here, owners delegate control to managers notwithstanding $\delta$ is large, for purely strategic reasons.

The above discussion can be summarised by the following proposition:

Proposition 4. When managers are impatient, owners' delegation decision is non-monotone in their discount factor $\delta$. They first delegate for low $\delta$ 's, then they do not delegate for intermediate $\delta$ 's and finally they delegate again for high $\delta$ 's. When $\delta \geq 9 / 17(\delta<9 / 17)$, owners always collude (play non-cooperatively) in the relevant variable.

\subsection{Patient managers $(\alpha \geq 9 / 17)$}

As we have seen in Section 5, if both owners delegate and managers are patient, the only sustainable equilibrium at the incentive stage entails non collusive behaviour with $\theta_{i}=\theta_{j}=0$, no matter what the owners' discount factor is. This also allows to establish that, regardless of the value of $\delta$, the unique subgame perfect equilibrium of the supergame entails owners choosing $(m, N)$ and managers choosing $C$. In order to gain a complete picture, it suffices to consider the range $\delta \in(25 / 81,9 / 17)$, where owners are not able to collude at the market stage. The payoff matrix of the repeated game is as follows.

\footnotetext{
${ }^{7}$ The letters in the bottom right corner of each cell indicate wheter owners collude or play Nash in the relevant variable As already mentioned, in case of one-sided delegation, Nash behaviour is the only option
} 


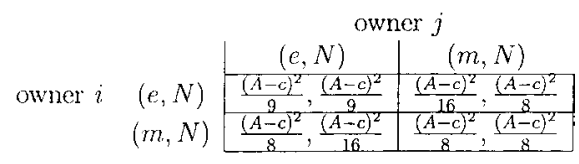

\section{Matrix 2}

The equilibrium $\{(m, N),(m, N)\}$ is the only Nash equilibrium of the game (as well as the only subgame perfect equilibrium of the supergame, obviously) and is also the Pareto optimum. Hence, if owners are unable to implicitly collude at the market stage, but managers are patient, then owners can use delegation as a tool to reach the collusive outcome through managers. Moreover, managers are required to simply maximise profits $(\theta=0)$, i.e. managers matter only because they are different people in that they have a different discount factor allowing them to reach the collusive outcome, but not because they have a different objective function.

We can conclude that plugging Vickers' original setting in a two-sided repeated collusion game changes the conclusions quite dramatically, by making delegation an optimal choice not only when other players do not delegate, but also when everybody else delegates, if myopic owners can benefit from the behaviour of forward-looking managers.

The above findings can be summarised by the following proposition:

Proposition 5. When managers are patient, the owners' decisions are $(m, N)$ independently of the level of their discount factor $\delta$.

\section{Concluding remarks}

In this paper, we have analysed how, in a simple duopoly setting, the ability to collude for the two firms depends on the presence of delegation of output decisions.

When agents can collude, but owners cannot, then the critical discount factor is the same as in a normal duopoly without delegation. Hence, in this case delegation does not affect firms' ability to collude. When owners can collude, but agents cannot, then delegation makes collusion more difficult in that deviation along the individual best reply at the incentive stage becomes more attractive than deviation at the output would be if owners were running their respective firms themselves.

When both managers and owners can collude, we have two possible cases. If managers are patient, i.e. they would collude in a standard Cournot game, at the incentive stage the optimal non-cooperative incentive scheme coincides with the collusive incentive scheme. Hence, we conclude that managers will always behave non-cooperatively, enjoying however the collusive outcome.

If managers are unable to sustain collusion at the market stage, i.e. they would not collude in a standard Cournot game, the two-sided collusion game reveals a non-monotonicity in the delegation decision by owners, as their individual discount factor increases, i.e. as they become more patient. 
The results derived for the two-sided collusion case allowed us to reconsider the delegation dilemma of Vickers (1985). In the static game, delegation is the equilibrium, but it would be Pareto efficient for the two owners not to delegate. If, however, the possibility to collude at both the market stage and/or at the incentive stage is considered the conclusions change substantially. If managers are impatient, but owners are sufficiently patient and can collude, then delegation is the optimal strategy for owners in the repeated game. This is opposite to Vickers (1985), where patient owners would find it feasible not to delegate in the repeated game. If managers are patient, but owners are impatient, then again delegation is the optimal strategy for owners, because by delegating they can take advantage of managers' ability to sustain cartel behaviour, so that owners enjoy the collusive outcome anyway.

\section{Appendix A}

In the main text, we adopt the function $M_{i}=\pi_{i}+\theta_{i} x_{i}$ as the manager's maximand. This rewrites as follows:

$$
M_{i}=p x_{i}-\left(c-\theta_{i}\right) x_{i} .
$$

Consider now the managerial objective function introduced by Fershtman and Judd (1987), which is defined as a linear combination of firm's profits and revenues, $\Omega_{i}=$ $\alpha_{i} \pi_{i}+\left(1-\alpha_{i}\right) p x_{i}$, which rewrites as:

$$
\Omega_{i}=p x_{i}-\alpha_{i} c x_{i} .
$$

The owner chooses $\alpha_{i}$ to maximise profits. It is a matter of straightforward calculations to show that $M_{i}$ and $\Omega_{i}$ coincide if $\theta_{i}=\left(1-\alpha_{i}\right) c$. As an example, we prove that this is indeed the case in the one-shot delegation game. As usual, we solve the game by backward induction. At the market stage, managers maximise non-cooperatively their respective objective functions $\Omega_{i}$ and $\Omega_{j}$ in a Cournot fashion. This yields the following best reply function for manager $i$ :

$$
x_{i}=\frac{A-x_{j}-\alpha_{i} c}{2} .
$$

Notice that the output level increases as $\alpha_{i}$ decreases, i.e. as the weight attached to revenues in the managerial maximand increases. The optimal output level is $x_{i}\left(\alpha_{i}, \alpha_{j}\right)=\left(A+\alpha_{j} c-\right.$ $\left.2 \alpha_{i} c\right) / 3$, entailing profits $\pi_{i}\left(\alpha_{i}, \alpha_{j}\right)=\left[A+c\left(\alpha_{i}+\alpha_{j}-3\right)\right]\left[A+c\left(\alpha_{j}-2 \alpha_{i}\right)\right] / 9$ accruing to the owner of firm $i$, whose best reply at the first stage of the game is

$$
\alpha_{i}=\frac{6 c-A-c \alpha_{j}}{4 c} .
$$

If both owners delegate, then $\alpha_{i}^{\mathrm{N}}=\alpha_{j}^{\mathrm{N}}=(6 c-A) /(5 c)$. Therefore, output levels are $x_{i}^{\mathrm{N}}=x_{j}^{\mathrm{N}}=[2(A-c)] / 5$ and profits are $\pi_{i}^{\mathrm{N}}(m ; m)=\pi_{j}^{\mathrm{N}}(m ; m)=\left[2(A-c)^{2}\right] / 25$, which coincide with the results obtained by Vickers (1985), see also Section 5.1 of this paper. In Vickers (1985), the optimal extent of delegation is $\theta_{i}^{\mathrm{N}}=\theta_{j}^{\mathrm{N}}=(A-c) / 5$, and it is immediately verified that $\theta_{i}^{\mathrm{N}}=\left(1-\alpha_{i}^{\mathrm{N}}\right) c$. Analogous considerations hold in the case of one-sided delegation. 


\section{Appendix B}

Consider first the case where managers maximise the joint objective function $M^{\mathrm{C}}=$ $M_{i}+M_{j}$. On the basis of Lemma 1, we impose $\theta_{i}=\theta_{j}=\theta$. The FOC for joint surplus maximisation is

$$
\frac{\partial M^{\mathrm{C}}}{\partial\left(x_{i}+x_{j}\right)}=A+\theta-c-2\left(x_{i}+x_{j}\right)=0
$$

from which

$$
x_{i}+x_{j}=\frac{A-c+\theta}{2} .
$$

To keep the symmetry of the game we assume that $x_{i}^{\mathrm{C}}=x_{j}^{\mathrm{C}}=x^{\mathrm{C}}=(A-c+\theta) / 4$. Then, solving and simplifying yields

$$
M_{i}^{\mathrm{C}}=\frac{(A-c+\theta)^{2}}{8}
$$

as the individual collusive payoff. Easy although tedious calculations are required to check that

$$
M_{i}^{\mathrm{N}}=\frac{(A-c+\theta)^{2}}{9} ; \quad M_{i}^{\mathrm{D}}=\frac{9(A-c+\theta)^{2}}{64} ; \quad M_{i}^{\mathrm{Ch}}=\frac{3(A-c+\theta)^{2}}{32},
$$

so that $M_{i}^{\mathrm{D}}>M_{i}^{\mathrm{N}}>M_{i}^{\mathrm{Ch}}$, and the punishment is credible. The critical discount factor $\bar{\alpha}$ (see Eq. (7)) turns out to be unaffected by the separation between ownership and control.

\section{References}

Abreu, D , 1986 Extremal equilibria of oligopolistic supergames Journal of Economic Theory 39, 191-225

Abreu, D, Pearce, D, Stacchetti, E, 1986 Optimal cartel equilibria with imperfect monitoring Journal of Economic Theory 39, 251-269

Albæk, S , Lambertini, L , 1998 Collusion in differentiated duopolies revisited Economics Letters, 59, 305-308

Barcena-Ruiz, J C , Paz Espinoza, M , 1996 Long-term or short-term managerial contracts Journal of Economics and Management Strategy 5, 543-559

Basu, K, 1995 Stackelberg equilibrium in oligopoly: an explanation based on managerial incentives Economics Letters 49, 459-464

Baker, G P, Jensen, M C , Murphy, K J , 1988 Compensation and incentives: practice versus theory Journal of Finance 43, 593-616

Chang, M , 1991 The effects of product differentiation on collusive pricing International Journal of Industrial Organisation 9, 453-469

d'Aspremont, C , Jacquemin, A , Gabszewicz, J J , Weymark, J , 1983 On the stability of collusive price leadership Canadian Journal of Economics 16, 17-25

Deneckere, R, 1983 Duopoly supergames with product differentiation Economics Letters 11, 37-42

Donsimoni, M -P, 1985 Stable heterogeneous cartels International Journal of Industrial Organisation 3, 451-467

Donsimoni, M -P, Economides, N , Polemarchakis, H, 1986 Stable cartels International Economic Review 27, 317-327

Fershtman, C, 1985 Internal organisations and managerial incentives as strategic variables in a competitive environment International Journal of Industrial Organisation 3, 245-253

Fershtman, C , Judd, K, 1987 Equilibrium incentives in oligopoly American Economic Review 77, 927-940 
Fershtman, C , Judd, K , Kalai, E , 1991 Observable contracts: strategic delegation and cooperation International Economic Review 32, 551-559

Friedman, J W, 1971 A non-cooperative equilibrium for supergames Review of Economic Studies 38, 1-12

Gibbons, R, 1992 A Primer in Game Theory, Harvester-Wheatsheaf, Englewood Cliffs, NJ

Green, E J , Porter, R , 1984 Non-cooperative collusion under imperfect price information Econometrica 52, $87-100$

Häckner, J, 1994 Collusive pricing in markets for vertically differentiated products International Journal of Industrial Organisation 12, 155-177

Häckner, J , 1995 Endogenous product design in an infinitely repeated game International Journal of Industrial Organisation 13, 277-299

Katz, M L , 1991 Game-playing agents: unobservable contracts as precommitments RAND Journal of Economics $22,307-328$

Lambertini, L , 1997 Prisoners' dilemma in duopoly (super)games Journal of Economic Theory 77, 181-191

Lambertini, L , 2000 Extended games played by managerial firms, Japanese Economic Review, 51, 274-283

Lambertini, L , Poddar, S , Sasaki, D , 1998 Standardisation and the stability of collusion Economics Letters 58, 303-310

Murphy, K J , 1985 Corporate performance and managerial remuneration: an empirical analysis Journal of Accounting and Economics 7, 11-42

Polo, M, Tedeschi, P, 1992 Managerial contracts, collusion and mergers Ricerche Economiche 46, 281-302

Rees, R , 1985 Cheating in a duopoly supergame Journal of Industrial Economics 33, 387-400

Ross, T W , 1992 Cartel stability and product differentiation International Journal of Industrial Organization 10, $1-13$

Rotemberg, J, Saloner, G, 1986 A supergame-theoretic model of business cycle and price wars during booms American Economic Review 76, 390-407

Sklivas, S D , 1987 The strategic choice of managerial incentives RAND Journal of Economics 18, 452-458

Vickers, J , 1985 Delegation and the theory of the firm Economic Journal 95 (Conference Papers), 138-147

Zábojník, J , 1998 Sales maximisation and specific human capital RAND Journal of Economics 29, 790-802 